\title{
Comparison of C:N:P stoichiometry in the plant-litter-soil system between poplar and elm plantations in the Horqin Sandy Land, China
}

\author{
KAI WANG ${ }^{1}$, Risheng Zhang ${ }^{2}$, Lining Song ${ }^{3}$, and Tao Yan ${ }^{4}$ \\ ${ }^{1}$ Liaoning Technical University \\ ${ }^{2}$ Liaoning Institute of Sandy Land Control and Utilization \\ ${ }^{3}$ Institute of Applied Ecology Chinese Academy of Sciences \\ ${ }^{4}$ Lanzhou University
}

November 23, 2020

\begin{abstract}
Afforestation is among the most effective means of preventing and controlling desertification. Silver poplar (Populus alba) is commonly planted tree species for afforestation of the Horqin Sandy Land of China. However, this species has exhibited some drawbacks such as top shoot dieback, premature senescence and mortality, and soil and ecosystems degradation. In contrast, Siberian elm (Ulmus pumila) rarely experiences these problems in the same regions. Ecological stoichiometry plays a vital role in exploring ecological processes and nutrient cycle relationships in plant-litter-soil systems. We measured $\mathrm{C}, \mathrm{N}$, and $\mathrm{P}$ concentrations in leaves, branches, roots, litter, and soils and analyzed $\mathrm{N}$ and $\mathrm{P}$ resorption efficiencies, and stoichiometric homeostasis in elm and poplar plantations in the Horqin Sandy Land. The results showed that soil C and N concentrations, $\mathrm{C}: \mathrm{P}$, and $\mathrm{N}: \mathrm{P}$ were greater in the elm plantation than in the poplar plantation. The plant $\mathrm{N}$ concentrations, C:P, and $\mathrm{N}: \mathrm{P}$ and litter $\mathrm{N}$ and $\mathrm{P}$ concentrations were greater, whereas $\mathrm{N}$ and $\mathrm{P}$ resorption efficiencies were lower, in the elm plantation than in the poplar plantation. Generally, elm exhibited greater homeostasis than poplar. These findings indicate that poplar exhibited more developed internal nutrient conservation and allocation strategies but poor nutrient accumulation in soil, which may contribute to degradation of poplar plantation. In contrast, elm tended to return more nutrients to the soil. Therefore, compared with poplar, elm may be a more suitable afforestation tree species for the Horqin Sandy Land, where it may promote the accumulation of soil nutrients and enhance ecosystem stability.
\end{abstract}

\section{Hosted file}

Manuscript.pdf available at https://authorea.com/users/378022/articles/494614-comparison-ofc-n-p-stoichiometry-in-the-plant-litter-soil-system-between-poplar-and-elm-plantationsin-the-horqin-sandy-land-china 